\title{
Study on the Improvement of Chinese Contract System Based on Smart Contracts
}

\author{
Chengrong CHEN \\ Wuhan University of Technology School of Arts and Law
}

\begin{abstract}
Although the smart contract as the new product in the era of block chain contract shall not be only limited to the property-related agreements stipulated by the Contract Law of People's Republic of China, the Chinese contract provisions shall be perfected accordingly due to its contract attribute. In order to promote the formation and validity of the smart contract, the full capacity requirements for civil conduct of the parties to the property-related contract as well as the formulation of "Withdrawal Provisions" and the connotation of social public interests shall attract legislators' attention. But in view of two major features of smart contract, on the one hand, the legislators shall consider distinguishing the remedies of continuous contract and instant contract; on the other hand, the legislators shall perfect the remedy system for the "Alteration" of smart contracts in the process of waiting for verification.
\end{abstract}

\section{Keywords-Smart contract; Block chain; Contract system}

\section{INTRODUCTION}

In 2008, Satoshi Nakamoto introduced the Bitcoin payment system and its underlying technology -- block chain technology for the first time in the article entitled as Bitcoin: A Peer-toPeer Electronic Cash System. Hereafter, the block chain entered the golden period of development which was reflected by the breakthrough of the key technology - smart contract technology in the block chain system and the block chain decentration was realized by the technology [1]. At present, the block chain based smart contract is mainly applied into the commercial events in the fields such as finance and Internet of Things, which realized the anonymous transactions without the third-party involvement, and such transactions are traceable, but irreversible.

Although the block chain based smart contract possesses the contract attribute, it, as the new product in the era of block chain contract, has certain differences from traditional contracts, and the legal issues involved herein shall be paid the full attention. There are no clear and enough provisions on the smart contracts in the existing Chinese contract system, therefore it is necessary to perfect the relevant domestic standards to ensure that the smart contracts are subject to the institutional framework of contract law in China and better

${ }^{1}$ Thomas Bocek. Digital Marketplaces Unleashed. Springer-Verlag GmbH. 2017-09-15: 169-184. ISBN 978-3-662-49274-1.

${ }^{2}$ Author: Fang LANG, Primary Investigation of Legal Problems related to Smart Contracts based on Block Chain, Journal of Weifang University, Page 56, Issue No.3, 2018.

${ }^{3}$ Refer to 44-7061 "C. Smart contracts may exist in commerce. A contract relating to a transaction may not be denied legal effect, validity of enforceability solely because that contract contains a smart contract term." stated in the Act (2417) issued by House of Representatives of Arizona. serve the social economy.

\section{DEFINITION OF SMART CONTRACT}

\section{A. Concept and Contract Attribute of Smart Contract}

In 1994, the academic Nick Szabo defined the smart contract at the theoretical level for the first time: "Smart contract is a set of promises defined in the digital form, which includes the agreement that the contracting party, according to the smart contract, is entitled to perform these promises ", the smart contract is defined as the embedded contract for performing contract terms. ${ }^{1}$ At present, the smart contract requires to be transformed into the actual application from the pure theory by means of the block chain technology. While the smart contract is manifested as one segment of automatically executable and tamper-resistant codes for recording the terms and conditions of a certain contract on the block chain in the block chain system; Or it can be interpreted as one algorithm with the self-verification and performance functions in the computer system [2].

The concept definition of the smart contract will be constantly adjusted with the constant development of smart contract technology, however the contract attribute of smart contract has been recognized by many academics from the legal perspective, "Smart contract is the contract which can replace the traditional contract by means of block chain technology or one new form contract with the legal effectiveness." Some Chinese academics clearly defined the smart contract as the named contract (typical contract) or included the smart contract into the unnamed contract (nontypical contract) at the early period based on the suggestions on the specificity of smart contract in the Contract Law of People's Republic of China².

\section{B. The Contract Law in China shall be Modified Accordingly}

Although the smart contract is mainly applied into the ecommerce at present, and Arizona also published an act in America for the first time in 2017 to clearly protect the smart contract, the act defined that the "Smart Contract" is related to the commercial transactions, but the author thinks that the smart contract shall not be included into the Contract Law of People's Republic of China ${ }^{3}$. Article 2 of the General Rules of the Civil Law specifies that: "The civil laws regulated the personal relation and property relation among the civil subjects of the natural persons, legal persons and unincorporated organizations with the equal standing." While Article 2 of the 
Contract Law specifies that: "For purposes of this Law, a contract is an agreement among natural persons, legal persons and other organizations with equal standing, for the purpose of establishing, altering and discharging a relationship of civil rights and obligations. An agreement concerning any personal relations such as marriage, adoption and guardianship shall be governed by other applicable laws. ", and according to the aforementioned terms, the property relation among the civil subjects is regulated by the Contract Law of People's Republic of China. The smart contract technology in the block chain system is intended to record the agreement information, including the conditions of smart performance with the identifiable procedure code, and shall not be only limited to the property-related agreement. The property disposal, and even the "critical friendship behavior" [3] and "Scherzerkl rung" referred in the German laws involved in the future status contract may also be included into the application of smart contract in theory with the promotion of smart contracts. ${ }^{4}$ However, even though the adjustment scope of the Contract Law of People's Republic of China will not cover the smart contracts, the existing contract system in China certainly will be affected due to the promotion of smart contracts with the contract attribute and in consideration that the Electronic Commerce Model Law of the People's Republic of China just approved is going to come into effect, therefore the Contract Law in China shall be modified accordingly.

\section{THE PERFECTION OF CONTRACT SYSTEM IN CHINA}

UNDER THE INVESTIGATION OF SMART CONTRACT VALIDITY

The legal effectiveness of smart contracts in China shall be determined in combination with Article 143 of the General Rules of the Civil Law of the People's Republic of China and the Contract Law of People's Republic of China due to its contract attribute, and the concluded and valid contract shall meet the following three conditions: All parties to the contract shall have the corresponding capacity for civil conduct; Their offers and promises are true and identical; They shall not violate the mandatory provisions of the laws and administrative regulations, the public order and good custom. The validity and effectiveness of smart contracts are the premises for the feasible application, and how to perfect the Contract Law to guarantee the validity and effectiveness of smart contracts shall be paid close attention.

\section{A. Opinion of the Standardization and Perfection of} Specification under the Investigation of Capacity for Civil Conduct

The parties to the contract who are engaged in the civil and commercial events including the conclusion of smart contracts must have the capacity for civil conduct, the users in the block chain have been required real-name registration at present, but the "Anonymous Credit" established among users by the consensus algorithm and other technologies is intended to decentralize, thus realizing the transaction cost reduction and privacy protection [4]. The one problem may be caused therefrom that the contracts with the defect in the effectiveness concluded by these persons without capacity for civil conduct and with the limited capacity for civil conduct are difficult to be standardized. It is very difficult for us to require the network platform operators to judge the capacity for civil conduct of the parties concerned in the internet transaction every time during the practice, and the Article 48 of the Electronic - Commerce Model Law of the People's Republic of China to be executed specifies that: "The conclusion or performance of a contact by E-commerce parties through the automatic information system shall have legal effects on the parties using the system. The parties in E-commerce are presumed with corresponding capacity for civil conduct. However, this excludes circumstances with sufficient counter evidences against the presumption." But for the conclusion of smart contracts that Ecommerce agreement are difficult to be interpreted for average persons, I think that the parties to the contract shall have the full capacity for civil conduct in my opinion. But the author thinks that whether the Contract Law can clearly specify that for the property-related contract concluded in the form of smart contract, its parties concerned require to have the full capacity for civil conduct in principle. Additionally, it is recommended to perform the real name authentication of personal accounts in the block chain system in order to better support the implementation of newly supplemented provisions and also better investigate the contracts concluded for the purpose of illegal criminal activities, for example the sales contract intended for money laundering will not be drowned in the ocean of internet transactions.

\section{B. Opinion of the Standardization and Perfection under the Investigation of Declaration of Will}

The offers and promises in the smart contracts shall be deemed as the declaration of intention made in the nondialogue manner, and its effectiveness is subject to the principle of arriving to make the internet speed and system settings become the factors may affect the conclusion time of smart contracts. In the case that there is no clear limitation on the transaction time between the parties to the contract, the smart contract may be concluded in the 24/7 (all-weather) commercial activities. The offers and promises in the smart contract shall not be withdrawn and revoked at present due to the technical limitations [5]. For the smart contracts concluded in the real activities, the contract purpose of one party concerned may not be achieved by such smart contracts concluded and have come into effect because the conclusion time isn't consistent with the transaction practices of parties concerned, etc.[6] Moreover, the smart contract concluded by the parties concerned by using "the automatic information system" stated in the Article 51 of the Electronic - Commerce Model Law of the People's Republic of China is prone to cause many agreements without a true and inconsistent declaration of intention, thus resulting in the termination, breach and other problems. Author thinks that if the offeror and acceptor concerned in the smart contract can be given the "Withdrawal Terms" available in the certain occasion under which the pecuniary benefit is more important than time interest by means of the Contract Law of China by reference to the "time limit for promises" specified for the acceptor in the Article 19 of the Contract Law of People's Republic of China and under the allowable conditions of block chain technology in the future, it will add one buffering function to the smart contract with the self-verification and automatic performance such that

\footnotetext{
${ }^{4}$ The term used in the Article 118 of German Civil Code is "Scherzerkl rung"..
} 
the autonomy of will of the parties to the smart contract can be satisfied more sufficiently.

\section{Opinion of the Standardization and Perfection under the Investigation of Validity ${ }^{5}$}

In order to ensure the correctness and completeness of contract contents recorded, the current smart contract technology is designed to transform the contract contents reached by the parties to the transactions into one character string by the hash algorithm ${ }^{6}$. More precisely, it calculates one hash value for the smart contract set concluded with an interval of certain time [7]. Compared to the traditional contract contents which are reflected by the languages and words all over the world, the hash value - encryption operation code is difficult to be understood by common traders. We require the smart contract service platform to offer relevant laws prior to the conclusion of smart contracts by the parties concerned, but the document information uploaded by the parties to the transactions has been transformed into the highly abstracted hash value during the performance period of smart contract, and the current technologies are insufficient to judge whether a certain hash value violates the mandatory provisions of laws and administrative regulations, let alone to affirm whether it violates the common public order and good custom. In such case, the legality review can only track the data source, i.e. the original contract text. The increased enforcement costs may cause the legal supervision and management of the smart contracts are focused on the proactive and post-mortem regulation and supervision. Additionally, the affirmation on the smart contracts in the block chain system violating the legal provisions is mainly based on the Article 52 of the Contract Law of People's Republic of China. For the fourth reason "harm to the public interests" for invalidity listed herein, its definition standard is still a difficult problem in the legal circles. The definition of such term in the field of smart contracts is more difficult than that in the traditional fields, there must be more and more smart contracts certainly concluded that will harm the benefits of the majority certainly and even the social public interest as the number of smart contract users is gradually increased, therefore legislators shall pay close attention.

\section{THE PERFECTION OF CONTRACT SYSTEM IN CHINA UNDER THE INVESTIGATION OF SMART CONTRACT FEATURES}

In the block chain system, the two major features of smart contracts different from common contracts are irrevocability and automatic performance, i.e. the contract contents can't be alternated and the contract performance is independently judged by the computer procedure. While the smart contract as the product of autonomy of will, how to ensure that the smart contracts more satisfy the requirements for the parties' freedom of will in the performance process under the contract law framework in China has an important practical significance.

\footnotetext{
${ }^{5}$ The "Act" referred herein includes the mandatory provisions specified in the laws and administrative regulations, public order and good custom.

${ }^{6}$ Menezes, Alfred J.; van Oorschot, Paul C.; Vanstone, Scott A (1996). Handbook of Applied Cryptography. CRC Press. ISBN 0849385237.
}

\section{A. Legal Advice on the Irrevocability of Smart Contracts}

Contracts are incomplete due to the bounded rationality of parties to the contract in the complex information age. For this reason, the Contract Law specifies that the parties to the contract can change the contract through consensus negotiation to make the contract more satisfy the legal requirements and the real intentions of parties concerned. However, it is difficult to realize the requirement that the smart contract is changed by the parties concerned through consensus negotiation, and its irrevocability feature causes a huge impact on the existing contract system in China. It means that the contents of smart contract to be performed (including its performance method) will not be changed in the process of performing the smart contract upon the determination. Article 60 of the Contract Law specifies that the "parties concerned shall fully perform respective obligations as agreed", which not only the parties concerned are required to fully perform the contractual obligations, but also permitted to change the contract performance according to laws under the agreed or legal circumstances. The parties concerned often are willing to accept the changes in the contract performance by opposite party provided that the previous expectations of the parties concerned at the time of signing the contract can be still satisfied after the changes. It isn't an instant thing from the establishment to the performance of one smart contract, the smart contract must at least undergo the verification and the consensual imbedding time, and the original contract may be rigidified due to its irrevocability, thus resulting in increasing the performance costs borne by the parties concerned. Furthermore, even though the parties to the common contract have clearly agreed the contract contents are irreversible at the time of signing contract, if there are grounds for the changes in the situation in the process of performance and cause the contract is obviously unfair, and even more it is difficult to obtain benefits for one party in the process of continuous performance, the laws permit the parties concerned can change or terminate the contract and they are not liable for any negligence liability or liability for breach of contract. Because the contents of smart contracts are irreversible, the parties concerned not only violate the principle of equity and the principle of honesty and credibility in the civil laws, but also can only take the relief afterwards in most cases under the existing technology in the event of changes in the situation.

Contracts can be classified into the continuous contract and instant contract. Compared to the instant contract, the continuous contract has the continuous performance time, there are new rights and obligations [8] created continuously between the parties concerned with the passage of performance time, thus the risk of changes in the situation and other incidents affecting the contract effectiveness is higher. However, the performance benefits have been received by the receiving party can't be returned, namely the previous condition can't be recovered in the event of aforementioned grounds. Therefore, it can be considered to discriminatively legislate on the part of contract relief system such as the contract change, contract termination, fault liability, liability for breach of contract, etc. after clearly classifying various specific contracts into the continuous contract and instant contract. Additionally, the block chain platform shall also distinguish the transaction type into the continuous contract 
and instant contract and then introduce the interim verification mechanism for these smart contracts such as lease within the scope of continuous contract, and the parties to the smart contract can timely take the legal relief in the process of performance. Such measure not only can promote the connection between the relevant provisions of smart contracts and the existing contract system in China, and but also accords with the "Electronic service provider shall freely offer the reconciliation services and the trading records in the past three years to users" specified in Paragraph 3, Article 53 of Electronic - Commerce Model Law.

\section{B. Legal Advice on the Automatic Performance of Smart Contracts}

The contract purpose of both parties will be realized or not realized depending on whether the conditions for the automatic performance of smart contracts can be satisfied. The smart contract is designed to realize the automatic performance function by the algorithmic procedure under the block chain technology, its basic working principle is similar to the judgment mechanism based on the computer programming language "if-then" statement, and the algorithmic procedure will enable the computer system to automatically perform the specific promise code, then the corresponding contract terms will be performed after receiving the specific data indicating that the conditions for the automatic performance are satisfied.[9] The satisfaction of conditions for the automatic performance of smart contracts can't be separated from the subjective analysis in the practice even though there are abstracted and objective codes. On the one hand, the original contract contents recorded by the smart contract are expressed by human language regardless of writing or oral form, the languages are multivocal in nature, then the smart contract codes transformed from the languages and words will be more ambiguous. On the other hand, how to embed the oral terms, transaction practices and other non-written contents into the binary codes will affect whether the smart contract can completely reflect the declaration of will of the parties to the transactions. Therefore, the edition of automatic performance conditions will affect the applicability of smart contracts. Furthermore, what is it exactly deemed that the triggering conditions would have been satisfied? The triggering conditions set are very strict, and may cause the smart contract can't be performed at all. But if the triggering conditions are too loose, the requirement for binding the parties concerned to fully perform the contractual obligations can't be met.

In order to realize the automatic performance of smart contracts, the smart contract concluded can be embedded into the block chain only after the certain verification and the time for the consensus, for example "miner" completes "mining" referred in the Bitcoin agreement, i.e. the time required for reaching consensus is about $10 \mathrm{~min}$. The time required for waiting verification is increased, and even exceeds $12 \mathrm{~h}$ as the number of unconfirmed transactions is gradually increased. ${ }^{7}$ The excessive time for waiting verification in the trading process will cause the contract "alternation". What are the circumstances under which the benefit lost or the failure to realize the contractual purposes caused by the contract "alternation" in the process shall be deemed as the attention

\footnotetext{
${ }^{7}$ Anonymity. The number of unconfirmed transactions based on the whole network breaks through 10000 again, and Can Bitcoins be further used for payment? [DB/OL] (2018-05-18) [2018-09-10]. https://www.sohu.com/a/232058262_130302.
}

obligation of the parties to the contract in the process of constituting contract? The relevant legal provisions shall be clearly defined. However, it is a difficult technical problem in the field of smart contracts that how to investigate and affix the fault liability of parties concerned in the event that the attention obligation is violated, thus the smart contracts should be guided according to relevant standards.

\section{CONCLUSION}

The smart contracts under the block chain technology are the computer transaction agreement with irrevocability and automatic performance, it brings a huge impact on the existing contract system in China, even more the fault obligation and liability for breach of contract in the process of applying the smart contracts can't be investigated and affixed, and the article only states the legal advice based on the definition, effectiveness and features of smart contracts. The General Rules of the Civil Law of the People's Republic of China approved by voting in 2017 represents that China entered the new legislative period of civil law system, and the Contract Law in China shall perfect the relevant provisions related to the smart contracts such that the smart contracts are subject to the legal framework of Contract Law.

\section{REFERENCES}

[1] Han SU. China Block Chain Industry White Paper in 2018 issued by Ministry of Industry and Information Technology of the People's Republic of China [J]. China Auto Parts Market, 2018(02): 15.

[2] J. Dax Hansen, Carla L. Reyes. Legal Aspects of Smart Contract Applications [R/OL]. 2017-05. Https: //www.perkinscoie.en/newsinsights/legal-aspects-of-smart-contract-applications.html.

[3] Qingyu ZHU. General Introduction to Civil Law (Edition 2) [M] Beijing: Beijing University Press, 2016.

[4] Delin LIU. Current Situation, Problems and Suggestions of Research, Development and Application of Blockchain Smart Contract Technology in the Finance Field [J] Reform Exploration, 2016(10).

[5] Run ZHOU, Ying LU. Influence of Smart Contracts on Chinese Contract System and its Countermeasures [J]. South China Finance, 2018(05): 93-98.

[6] Shiyuan HAN. Pandect of Contract Law [M]. Beijing: Law Press China, 2011.

[7] Yong YUAN, Xiaochun NI, Shuai ZENG, and Feiyue WANG. Development State and Future Trends of Blockchain Consensus Algorithm [J/OL]. ACTA AUTOMATICA SINICA: 1-12[2018-09-27]. https://doi.org/10.16383/j.aas.2018.c180268.

[8] Jingwei LIU. Contract Law: China Democratic Law Press, 2014.

[9] DorianS. Nakamoto. Bitcoin: A Peer-to-Peer Electronic CashSystem. [DB/OL]. [2008.11.1]. http: / metzdowd.com. 